\title{
The Extra-textual Reasons for the Popularity of Yang Bi's Translation of Vanity Fair
}

\author{
Hui $\mathrm{Yu}$ \\ Army Academy of Artillery and Air Defense \\ Hefei, China
}

\begin{abstract}
Yang Bi is one of the famous translators in the history of Chinese literary translation. Her representative work - "Vanity Fair" has been considered one of the classical literary translation works in China. Her language in the translation is not only fluent and original but also beautiful and meaningful. Besides, her translation reconstructs the literary style of the original to the greatest extent. This essay is going to explore the reasons for the popularity of Yang Bi's translation of Vanity Fair from extra-textual aspects - the background of the author, (such as her family, her pre-school education and school education, the good command of English and Chinese etc.), her serious and responsible working style, the preferential academic background during Yang Bi's time and the choice of text.
\end{abstract}

Keywords-Yang Bi; Vanity Fair; literary translation; extratextual

\section{INTRODUCTION}

Yang Bi's representative work - "Vanity Fair" has been considered one of the classical literary translation works in China since its publication by People's Literary Publishing House in 1957. It is a wonderful representative of the translated literary works in China. Good at imitating and lively and humorous characters was coincidental with Thackery's humorous literary style. Yang Bi's well-educated family provided her good pre-school education which helped her lay solid foundation in Chinese. Her English teaching experience in Tsinghua University and Zhen Dan University was of great help to improve her English. All these show that the competence of a translator is the foundation and necessity for the good translation. In addition, the two sessions of National Conference of Translation also provided good academic environment for literary translation. Through analyzing the target language text, the choice of words, the use of four-character phrases and the reproduction of the original especially the reproduction of the image of the original are the main reasons for the success of Yang Bi's version.

\section{THE COMPETENCE OF LITERARY TRANSLATOR}

It's said that a translator serves as a bridge, connecting the original author, the original work, the translated work and readers. To a translator, he or she must appreciate the work to be translated and have bilingual or even bicultural capacity so as to thoroughly understand the original text.

\section{A. Bilingual Competence}

For a translator, the basic requirement is a good command of his or her mother language and foreign language. That's the reason why many literary translators are not only masters in translation but also famous Chinese writers, such as Ba Jin, Xiao Qian, Guo Moruo, Yang Jiang, Qian Zhongshu, Yang Bi, Jia Pingao, to name but a few.

"First of all, the translator must possess linguistic competence in both languages. As far as English is concerned, we must know (a) how propositions are structured (semantic meaning), (b) how clauses can be synthesized to carry propositional content and analyzed to retrieve the content embedded in them (syntactic knowledge), and (c)how the clause can be realized as information-bearing text and the text decomposed into the clause (pragmatic knowledge). As for the Chinese language, having a good command of such knowledge as vocabulary and wordformation, sentence structure and natural expression is certainly an indispensable prerequisite for a qualified translator." (Chen Zhaowei : 2007)

\section{B. Wide Knowledge}

A translator has to be able to be knowledgeable in more than one or two areas. Language is the carrier of culture. Culture is the mirror of the society. The knowledge involved in the target text is mostly related to the knowledge various fields. As the translator, he or she must has a natural curiosity about many areas of society, and an interest in accumulating one's vocabulary in a variety of fields.

"On the other hand, one must be sensitive to certain basic principles of interlingual communication, and on the basis of these principles, acquire the necessary skill through extensive practice. Quite clearly, a theory of translation is not enough. One must put it into practice. Reading a book about sports as swimming, skiing, or riding a bicycle will not make one really involved in these activities without practice. But practicing a sport without a knowledge of how it should be engaged in can result in bad habits which may be difficult, if not impossible, to overcome. Accordingly, going about the task of translation with a false idea of what is really involved may not only result in poor translations, it may seriously harm one's chances to cultivate good habits."(Ma Xiaorong: 2002) 


\section{Bicultural Competence}

Translation is related to tow cultures: the source culture and the target culture. "Besides bilingual competence, a translator must possess communicative competence in both cultures. Cultural competence refers to the knowledge and ability possessed by the translator which permit him/her to create communicative acts-discourses-which are not only grammatical but socially means that he understands what happens when he/she sends a message from one culture to another, i.e. to understand subtle difference of meanings and connotations between cultures, between subcultures, between situations and contexts. If a translator fails in this aspect, it is very likely for him/her to produce an inappropriate text which may lead to misunderstandings, communication breakdowns and even conflicts."(Chen Zhaowei: 2007)

\section{A Sense of Responsibility}

Translating is a time-consuming task which also involves great energy. As Jin Di and Nida say, a translator must be involved in the task both with his or her time and spirit. The devotion to one's task will be ultimately decisive in the making of a good translator, as can be found in such striking evidence in the life of every past master of this difficult task. That is a translator's sense of responsibility towards the original text. "Translators act ideally as historians and demonstrate a fundamental respect for the original text as a sacred and inviolable form. To this end, every translator should strive for accuracy, precision and objectivism in his work."(Chen Zhaowei: 2007) Translation is dependent on the dissolution of the translator's ego: an absolute humility towards the text. The scholar Cheng Zhaowei in his book on literary translation proposed the three-level responsibility:

- A matter of responsibility for the original author

- A matter of responsibility for Chinese readers;

- A matter of artistic responsibility for the translated text (cf. Chen Fukang, 1992-1993:329)

\section{YANG BI'S COMPETENCE AS LITERARY TRANSLATOR}

\section{A. The Influence of Her Family}

Yang Bi was born in Shanghai in 1922 and before long she moved to Su Zhou with her whole family. So she almost spent her childhood in $\mathrm{Su}$ Zhou. Yang Bi grew up in an educated family. Both Qian Zhongshu and Yang Jiang are the famous writers and translators in Chinese literature field. Yang Bi's father Yang Yinhang was also a well-educated man. He once went to Japan in 1897 and America in 1899 for further study. In Yang Jiang's book "In Reflection of My Father",she still remembered clearly once her father said: " It's better to translate some valuable foreign literature works than write some meaningless passages." Undoubtedly, Yang Bi received good pre-school education in his family. Her father bought her ancient Chinese book when she was very young and she read her mother's book The Stone's Story. Thus Yang Bi laid very good Chinese foundation even when she was very young. Fu Lei, the famous translator and scholar in China, once asked Yang Bi to help his son Fu
Cong learn English and encouraged Yang Bi to translate the classic literature. Yang Bi turned to his brother-in-law Qian Zhongshu for advice. Qian said the old Chinese version of Thackery's Vanity Fair was not satisfying and suggested him re-translating it.

\section{B. Formal School Education}

Yang $\mathrm{Bi}$ was enrolled into Zhen Dan Female Arts\&Science College after middle school. The administrator of the college was an middle-aged British woman named Mother Thornton. After graduating from college Yang Bi went to Peking with Mother Thornton and stayed in Tsinghua University for one year as a teaching assistant and then came back to Zhen Dan University as an English teacher. While in college, Yang Bi once did a part-time job as a Chinese-to-English translator for International Labor Bureau for two or three years. It was said that she did the job very competently. Yang Bi's English level had been improved through her education, teaching practice and parttime job.

\section{Yang Bi's Characters}

Yang Bi was very quiet and temperate. But after she could walk she became a little bit naughty. There are two things she didn't like to do. One is washing face and the other is sleeping.

She was good at imitating and acting. She could vividly imitate her families' intonations, played the role in the movie and act it out. Therefore, she could always bring happiness wherever she went. When she was teaching English in $\mathrm{Fu}$ Dan University, she was very popular among students because her class was very interesting. Besides, she was straightforward. For some or other reasons, she didn't get married in her lifetime. In China during Yang Bi's time, if a lady didn't get married when she reached 25, she would become the other's laugh stocking. Some people said Yang Bi wasn't attractive to men because she didn't have "it" (which refer to something attract men). Yang Bi didn't care about that, just said: "as long as you got it, why bother I need?"

\section{Yang Bi's Good Command of Chinese and English}

Bilingual competence is of the significant factor in producing the successful translation for a literary translator. Many famous translators laid solid foundation in Chinese when they were young. Yang Bi laid a good foundation in Chinese when she was a little girl. She began reading lots of ancient books under the influence of his family since both her parents were well-educated. She also published some Chinese essays in the magazine named "Words of Soul" when she was a student.

\section{E. Yang Bi's Working Style}

Yang Bi's responsible and serious working style propelled her to translate Vanity Fair day and night even at the risk of her health. It was said that in order to enrich her Chinese vocabulary Yang Bi read the Chinese classics Dream in Red Mansion for several times. In order to hand in 
her translation to People's Literature Publishing House on time, Yang $\mathrm{Bi}$ worked day and night on her translation. Finally, she handed the translation version to the People's Publishing Press on time and got the highest payment. Unfortunately, her health had worsened after finishing the translation of Vanity Fair. When her version was printed again, the editor asked if there were some places needed changing. Yang Bi said "no" not because she was pretty satisfied with her translation but because her health didn't permit that.

\section{CONTEMPORARY POLITICAL AND ACADEMIC BACKGROUND}

It is a fact that literary translation work is always finished in a certain background including the political situation, the academic background and so on and so forth. Actually these factors have great effect upon translation especially the literary translation. We can easily find some examples to prove that. At the beginning of the 20th century, especially after May Fourth Movement, which was the turning point of the Chinese revolution, symbolizing the end of the old democracy revolution led by the bourgeoisie and the beginning of the new democracy revolution led by proletariat, that period of time produced lots of famous translators such as Lu Xun, Qu Qiubai and Li Dazhao, who combined their translation activities with their fighting against the feudalism and imperialism and established the realism route of literary translation in China. While for Yang Bi, who had done the literary translation in relatively free academic environment was mostly because of the two grand National Conferences on translation.

The first session of National Translation Conference was held on Nov.5---Nov.12 1951. The conference was directed to improve the translation quality and laid solid foundation for integrating the translation work into the socialism cause.

In order to improve literary translation and the quality of translation, the National Literary Translation Conference was held on Aug.19 1954. The famous writer and translator Mao Dun made a report titled "To Strive for improving literary Cause and translation quality". The conference was of great significance in literary translation history. The achievements of the conference were simply as follows:

Firstly, it made breakthroughs in literary translation theory building, and improved the literary translation to the artistic level.

Secondly, it propelled the establishment of the organized translation staff in China.

Last, it was the first literary translation conference in China and made great contributions in enhancing the position of literary translation.

The two National Conferences on the work of translation in China at that period of time provided good academic atmosphere for people who pursued literary translation cause for whole life. Anyhow, Yang Bi and the other translators benefited a lot from the two conferences. Lots of masterpieces in literary translation were produced during that period of time and Yang Bi's Vanity Fair was among them. Unfortunately, Yang Bi left her readers forever in 1966 when the whole country especially the literary field began to experience the "disaster". Imagine what if there was no such "disaster", how many other classical literary translation works could be produced.

\section{THE CHOICE OF THE TEXT}

Translating was at no time considered as a random activity. Mao Dun once stated that the purpose of literary translation were to develop new literary translation were to develop new literature and propagate new ideas when he published The tasks and Efforts of Researchers in the Field of New Literature in 1921. "The purpose of introducing western literature is to introduce their art of literature as well as progressive ideas of the world, and the latter of the two should be paid more attention to...."

The success of Yang Bi's Vanity Fair also owed to the choice of the text. Although it was Qian Zhongshu who suggested Yang Bi translated Vanity Fair, in my opinion, Qian thought Yang Bi was suitable to translate Vanity Fair since he was her brother-in-law who understood her well. It's said that translation is a process of choosing. The process of translation is complex and includes lots of choices, and the choice of translation goes through the whole process of translation activity. Thus, as the key role of the translation activity, the translator is confronted with all kinds of choices: at the translation preparation stage, he must decide what to translate, whose works to translate, and during the translation process, he must determine for whom to translate and how to translate among other considerations. Because of the limited space here we only focus on the choice of text---whose works to translate.

What to translate is the primary question prior to translating. Translators usually pay great attention to the choice of translation text. For example, Fu Lei once compared choosing translation text to making friends. And Liang Qichao considers the choice of translation text as the most important thing in translation action. 1 in this point, Xiao Qian stresses "loving the work", "I prefer to choosing sarcastic literature...this is my personal tendency." Fang Mengzhi also said: "A man of insight chooses translation text with the ambition of invigorating his nation and awaking his people, however, a mediocre man chooses translation text for entertainment. The translation text is up to translator to choose, who the dominator is." The above sayings show that translators indeed enjoy freedom of making choices and sometimes decide what to translate with strong personal preferences. Yang Bi's characters we have already mentioned in the above part that is very lively and energetic. We can also see Yang Bi's lively character from her Chinese prose from the chosen part in the above part. Thus, we can say her success of translation of Vanity Fair also attributes to the correct choice of text.

\section{CONCLUSION}

Yang Bi's translation of Vanity Fair has been regarded as one of the masterpieces which have reproduced the original 
style since its publication in 1957. Instead of exploring the textual reasons of the success of the translation, this thesis focused on extra-textual analysis of the success of Yang Bi's translation of Vanity Fair, which offered the readers a deep insight to the special features of Yang Bi's generation, Yang Bi's competence as a successful literary translator, the reasons why she chose to translate Vanity Fair, etc.

\section{REFERENCES}

[1] Chen Zhaowei. General Introduction of Literature[M]. Beijing: National Defense Press, 2007.

[2] Ma Xiaorong. On the Qualities of Translator and the Examination on the translated Book. Cheng Du: Si Chuan Normal University, 2002(4).

[3] Zhang Caifeng. "Bilingual Qualities-the Keys to the Successful Translation" [J], Chinese Journal (English Version) 2006,(2).

[4] Xu Jun. Translation Exploration and Thoughts[M]. Beijing: Foreign Language Teaching and Research Press, 2002.

[5] Yang Bi. Vanity Fair [M]. Beijing: People Literature Press, 1957. 